\title{
FAKTOR-FAKTOR YANG MEMPENGARUHI KEPUTUSAN MBR MEMBELI RUSUNAMI DI KOTA BEKASI (STUDI KASUS: SENTRALAND \& VIDA BEKASI)
}

\author{
FX. Mario Mailiando ${ }^{1}$, Nurahma Tresani ${ }^{2}$, dan Nasiruddin Mahmud ${ }^{3}$ \\ ${ }^{1}$ Mahasiswa Magister Teknik Perencanaan, Universitas Tarumanagara, Jakarta \\ Surel:mario_mailiando@yahoo.com \\ ${ }^{2}$ Dosen Magister Teknik Perencanaan, Universitas Tarumanagara, Jakarta \\ Surel: ntresani@gmail.com \\ ${ }^{3}$ Dosen Magister Teknik Perencanaan, Universitas Tarumanagara, Jakarta
}

\begin{abstract}
Simple Owned Flats, mostly known as Rusunami is one of the Government's efforts to provide decent housing, especially for low-income community groups (MBR) and to overcome the problem of housing backlog. An increase in population of around $4 \%$ every year, along with the increasingly limited availability of vacant land for housing, making the procurement of rusunami very important in the city of Bekasi. At present time, at the city of Bekasi 5 rusunami have been built and some of them are Bekasi Sentraland which was developed by Perumnas and Teras Alun-Alun, Bekasi which was developed by Gunasland. One hundred percent of Phase 1 Sentraland Bekasi's sales were completely taken by the MBR group, while Teras Alun-Alun only had $58.5 \%$ of its units sold. In addition, the majority of Teras Alun-Alun buyers are upper middle class and investors. This study will examine the factors that influence buying decisions in the Central Bekasi and the factors that influence lost customers not purchasing Teras Alun-Alun. This research uses quantitative method which will then be explained descriptively. This study found that the factors influencing the buying decision in Sentraland Bekasi were the affordable selling price of under $R p 200$ million / unit, the credibility of Perumnas as a trusted developer, and the concept of Sentraland Bekasi which was integrated with malls and offices. Whereas the factors that influence lost customers not to purchase the Teras Alun-Alun are the high selling price, which is above Rp. 300 million / unit, the location not being strategic, and the availability of many nearby, more affordable housing options within a $15 \mathrm{~km}$ radius of the Teras Alun-Alun.
\end{abstract}

Keywords: low-cost apartment, buying decision, MBR, Bekasi

\begin{abstract}
ABSTRAK
Rumah Susun Sederhana Milik atau Rusunami adalah salah satu upaya Pemerintah menyediakan rumah tinggal yang layak khususnya untuk kelompok masyarakat berpenghasilan rendah (MBR) dan untuk mengatasi masalah backlog kepemilikan rumah. Peningkatan jumlah penduduk yang bertambah sekitar 4\% setiap tahunnya ditambah ketersediaan lahan kosonguntuk perumahan yang semakin terbatas, membuat pengadaan rusunami menjadi sangat penting di kota Bekasi. Saat ini kota Bekasi telah memiliki sekitar 5 rusunami dan beberapa diantaranya adalah Sentraland Bekasi yang dikembangkan oleh Perumnas dan Teras Alun-Alun, Bekasi yang dikembangkan oleh Gunasland. Seratus persen penjualan tahap 1 Sentraland Bekasi terserap habis oleh kelompok MBR, namun Teras Alun-Alun hanya terserap sekitar 58,5\%. Selain itu, mayoritas pembeli Teras Alun-Alun merupakan kalangan kelas menengah ke atas dan investor. Penelitian ini akan meneliti mengenai faktor-faktor yang mempengaruhi keputusan membeli di Sentraland Bekasi dan faktor-faktor yang mempengaruhi lost customer tidak membeli di Teras AlunAlun. Penelitian ini menggunakan metode kuantitatif yang kemudian akan dijelaskan secara deskriptif. Penelitian ini menemukan bahwa faktor-faktor yang mempengaruhi keputusan membeli di Sentraland Bekasi adalah harga jualnya yang terjangkau yaitu di bawah Rp 200 juta/unit, kredibilitas Perumnas sebagai developer yang terpercaya, dan konsep Sentraland Bekasi yang terintegrasi dengan mall dan perkantoran. Sedangkan faktor-faktor yang mempengaruhi lost customer tidak membeli di Teras Alun-Alun adalah harga jualnya yang mahal yaitu di atas Rp 300 juta/unit, lokasinya yang tidak strategis, dan masih terdapat banyak pilihan hunian tapak dalam radius $15 \mathrm{~km}$ dengan harga jual yang lebih murah dibandingkan dengan Teras Alun-Alun.
\end{abstract}

Kata kunci: rusunami, keputusan membeli, MBR, Bekasi

\section{PENDAHULUAN}

Hunian merupakan salah satu kebutuhan dasar manusia sebagai tempat untuk menetap dan sebagai pendukung terciptanya rumah tangga yang berkualitas. Seiring dengan bertambahnya 
jumlah penduduk di kota membuat kebutuhan akan hunian semakin meningkat. Kementerian Pekerjaan Umum dan Perumahan Rakyat (KemenPUPR) mencatat sekitar 11,4 juta kepala keluarga (KK) di Indonesia tidak memiliki rumah pada tahun 2015. Pada tahun 2019, KemenPUPR menargetkan angka backlog kepemilikan rumah di Indonesia turun menjadi 6,8 juta KK. Target utama KemenPUPR adalah penyediaan hunian untuk masyarakat berpenghasilan rendah (MBR). (PUPR, 2016).

Menurut Todaro dan Stilkind (1985), kota-kota di Indonesia mengalami urbanisasi berlebih (over urbanization). Kondisi urbanisasi berlebih adalah kondisi kota-kota yang tidak mampu menyediakan fasilitas pelayanan pokok dan kesempatan kerja yang memadai kepada penduduk yang bermigrasi ke kota. Kondisi ini berdampak terhadap ketidakseimbangan antara kebutuhan dengan pasokan hunian, khususnya masyarakat berpenghasilan rendah yang tidak mampu mengakses atau membeli hunian di kota-kota besar dengan harga yang terjangkau.

Dalam upaya menurunkan angka backlog kepemilikan rumah, Pemerintah menerbitkan Paket Kebijakan Ekonomi XIII (paket 13) pada tanggal 25 Agustus 2016 (PUPR, 2016). Kebijakan ini bertujuan untuk mempercepat penyediaan perumahan yang layak dengan harga terjangkau bagi MBR. Untuk mendukung kebijakan tersebut, Pemerintah Indonesia telah mengeluarkan Peraturan Pemerintah No. 64 tahun 2016, tentang pembangunan perumahan masyarakat yang diharapkan dapat menjadi payung hukum dalam percepatan penyediaan perumahan.

Namun permasalahan backlog kepemilikan rumah tidak hanya dapat diselesaikan oleh Pemerintah semata. Sinergi antar seluruh stake holder juga dibutuhkan dalam menyelesaikan permasalahan ini. Keterbatasan lahan di area kota dan harga lahan yang semakin meningkat tanpa diimbangi dengan kemampuan membeli masyarakat membuat rusunami menjadi salah satu solusi efektif dalam menyelesaikan permasalahan backlog kepemilikan rumah.

Kota Bekasi merupakan salah satu kota di Indonesia yang terkena dampak peningkatan jumlah penduduk yang cukup tinggi setiap tahunnya. Menurut data Badan Pusat Statistik (BPS) Kota Bekasi, pada tahun 2016 jumlah penduduk di Kota Bekasi sekitar 2.803.283 jiwa. Pada tahun 2017, jumlah penduduk di Kota Bekasi meningkat menjadi 2.921 .020 jiwa atau sekitar 4,2\% dari tahun 2016. Akibat peningkatan jumlah penduduk ditambah ketersediaan lahan kosong yang semakin terbatas di Kota Bekasi, pembangunan perumahan vertikal menjadi sangat penting di Kota Bekasi (Badan Pusat Statistik Kota Bekasi, 2016).

Sentraland dan Teras Alun-Alun merupakan salah satu rusunami yang dikembangkan di Kota Bekasi. Sentraland Bekasi milik Perumnas merupakan bukti dukungan Pemerintah untuk mendorong berbagai pihak dalam penyediaan hunian untuk MBR (Mudzakir, 2016). Begitu juga dengan Teras Alun-Alun milik Gunasland diharapkan dapat berkontribusi dalam pengentasan permasalahan backlog kepemilikan hunian yang salah satu sasarannya adalah MBR (Erawan, 2017). Menurut Basuki, MBR yang dimaksud bukanlah warga miskin, melainkan keluarga yang memiliki pendapatan total kisaran hingga Rp 7 juta/KK (Mudzakir, 2016).

Berdasarkan penelitian awal yang dilakukan oleh penulis, Sentraland sukses menjual 100\% unitnya atau sebesar 183 unit di tahap 1 oleh kelompok MBR. Berbeda dengan Teras Alun Alun yang hingga tahun 2018 baru terserap sekitar 58,5\% atau sebesar 96 unit dalam 13 bulan. Selain itu, Teras Alun Alun lebih banyak diminati oleh kelompok menengah ke atas dan investor. Temuan ini tidak sesuai dengan sasaran Pemerintah yang menargetkan rusunami ditujukan untuk kelompok MBR. 
Terdapat 5 faktor yang mempengaruhi keputusan membeli atau tidak membeli Rusunami diantaranya harga jual, lokasi, promosi, fasilitas, dan pilihan pembiayaan (Mendrofa, Wibowo, Sofyan, Hendrawan, \& Witria, 2017). Dalam penelitian Nohed, 2013 menambahkan bahwa future value sekitar hunian turut menjadi faktor yang mempengaruhi keputusan pembelian rusunami. Perbedaan antara kedua rusunami tersebut mendorong penulis untuk melakukan penelitian lebih lanjut mengenai faktor - faktor yang mempengaruhi keputusan membeli rusunami di Sentraland Bekasi dan faktor - faktor yang mempengaruhi lost customer tidak membeli rusunami di Teras Alun Alun, Vida Bekasi.

Tujuan dari penelitian ini adalah untuk mengetahui faktor - faktor yang mempengaruhi keputusan membeli rusunami terhadap kelompok MBR di kota Bekasi. Adapun sasaran penelitian ini adalah sebagai berikut:

1. Mengidentifikasi faktor-faktor yang mempengaruhi keputusan MBR membeli rusunami di Sentraland Bekasi

2. Mengidentifikasi faktor-faktor yang mempengaruhi keputusan lost customer tidak membeli rusunami di Vida Bekasi

Melalui penelitian ini diharapkan dapat memperlihatkan faktor-faktor yang mempengaruhi keputusan MBR membeli huniannya dan memberikan masukan kepada Pemerintah sebagai bahan dalam menentukan kebijakan pemenuhan kebutuhan hunian khususnya di Kota Bekasi.

\section{METODE PENELITIAN}

Penelitian ini menggunakan metode penelitian kuantitatif. Data diperoleh melalui kuesioner terhadap 65 konsumen dari total 183 konsumen penjualan tahap 1 Sentraland Bekasi dan 60 lost customer Vida Bekasi sekitar dari total 140 lost customer Vida Bekasi, wawancara dengan manajer marketing Sentraland Bekasi dan Vida Bekasi, serta melakukan pengamatan lapangan.

Secara umum metode analisis yang digunakan adalah metode statistik deskriptif yang ditampilkan dalam bentuk tabel dan diagram untuk menggambarkan tingkat penyerapan pasar, profil pembeli rusunami, dan faktor faktor yang mempengaruhi keputusan membeli dan tidak membeli rusunami. Faktor faktor yang mempengaruhi keputusan membeli rusunami akan diolah dengan metode Likert Scale Analysis. Dalam penelitian skala likert dianggap sebagai skala interval. Analisis yang digunakan adalah one salmpe t test dengan menentukan mean dari tiap-tiap faktor yang kemudian akan diolah dalam bentuk relative rank index (RRI) untuk menentukan faktor yang paling dominan.

\section{HASIL DAN PEMBAHASAN}

\section{Gambaran Umum Kota Bekasi}

Kota Bekasi memiliki luas wilayah $\pm 210,49 \mathrm{~km}^{2}$. Dari total luas wilayah tersebut, $50 \%$ menjadi kawasan efektif perkotaan, 45,3\% menjadi kawasan perumahan, 3\% menjadi kawasan perdagangan dan sisanya untuk bangunan lainnya. Dinas tata kota Bekasi menyebutkan bahwa dari 45,3\% lahan yang dialokasikan untuk hunian, saat ini tinggal tersisa $8 \%$ atau 1,781 Ha (Jurnal Tata Kota Bekasi, 2014).

\section{Demografi Kota Bekasi}

Sebagai Kota Satelit Jakarta, Bekasi mengalami pertumbuhan penduduk setiap tahunnya. Pada tahun 2015, penduduk kota Bekasi bertambah 2,57\% dari tahun 2014. (Badan Pusat Statistik Kota Bekasi). Selain itu, kota Bekasi didominasi oleh kelompok usia produktif, yaitu 25-29 tahun. Jumlah penduduk pada kelompok usia ini adalah 10, $8 \%$ dari total penduduk kota Bekasi.

Pertumbuhan penduduk yang dialami kota Bekasi berimplikasi terhadap meningkatnya permintaan kebutuhan hunian. Dari total penduduk yang tinggal di Kota Bekasi, 59,7\% merupakan hunian milik 
sendiri, 18,5\% hunian berstatus sewa, dan 9,2\% hunian berstatus kontrak, sedangkan sisanya adalah hunian milik orangtua, rumah dinas, dan sebagainya. Dari persentase di atas menggambarkan bahwa masih ada sebagian rumah tangga kota Bekasi membutuhkan hunian sedangkan lahan untuk hunian di kota Bekasi semakin terbatas. Sehingga hunian vertikal dianggap sebagai salah satu solusi menangani masalah kebutuhan hunian di kota Bekasi.

\section{Perkembangan Rusunami di Kota Bekasi}

Dalam paparan Deputi Kemenpera bidang perumahan formal Kementerian Perumahan Rakyat Republik Indonesia mengenai percepatan Pembangunan Rusunami pada tahun 2007 mengatakan bahwa terdapat 10 kota besar di Indonesia yang dianggap perlu membangun rumah susun. Sepuluh kota besar tersebut diantaranya Jabodetabek (Jakarta, Bogor, Depok, Tangerak, dan Bekasi), Kartamantul (Yogyakarta, Sleman, dan Bantul), Semarang dan sekitarnya, Surabaya dan sekitarnya, Medan dan sekitarnya, Batam dan sekitarnya, serta Palembang dan sekitarnya (Dirgantara, 2016). Pembangunan rusunami terbanyak adalah di Jabodetabek. Perbandingannya dengan kota-kota lainnya adalah 60,4\% di Jabodetabek, 22,4\% di Pulau Jawa selain Jabodetabek, dan 17,2\% di luar pulau Jawa.

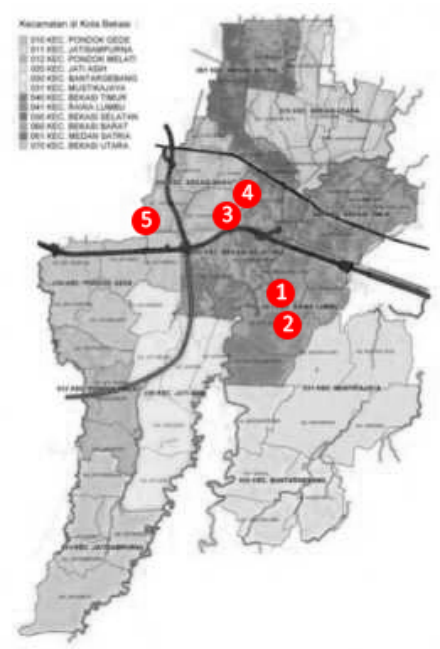

Gambar 1. Peta Persebaran Rusunami di Kota Bekasi

Tabel 1. Tabel Persebaran Rusunami Kota Bekasi

\begin{tabular}{cllc}
\hline No & \multicolumn{1}{c}{ Nama Rusunami } & \multicolumn{1}{c}{ Pengembang } & Jumlah Unit \\
\hline 1. & Sentraland Bekasi & Perumnas & 1.117 \\
\hline 2. & Teras Alun Alun & Gunas Land & 164 \\
\hline 3. & Apartemen Mutiara Bekasi & PT Gayaland Prokencana & 800 \\
\hline 4. & Centerpoint Bekasi & $\begin{array}{l}\text { PT Triputra Multi Graha } \\
\text { Pertiwi \& Perumnas }\end{array}$ & 800 \\
\hline 5. & Kalimalang Residence & PT. Mitra Safir Sejahtera & 1.092 \\
\hline
\end{tabular}

Sumber: (Dody, 2015) dan olahan penulis, 2018

\section{Gambaran Umum Sentraland Bekasi}

Sentraland Bekasi yang berlokasi di Jl. Raya Siliwangi KM 7, Kelurahan Bojong Rawalambu, Kecamatan Rawalumbu merupakan bagian dari pembangunan terpadu (mixed use development) di atas lahan seluas 2,08 Ha dan dikembangkan oleh anak perusahaan Perum Perumnas yaitu PT Propernas Griya Utama (PGU). Sentraland Bekasi direncanakan memiliki 5 tower dengan pembagian 4 tower untuk hunian dan 1 tower untuk komersial berupa mall dan perkantoran. 
Pada tahap pertama dikembangkan 2 tower yang masing-masing terdiri dari 24 lantai dengan jumlah unit sebanyak 1.117 unit.

Sentraland Bekasi memiliki 2 tipe unit yaitu tipe studio dengan ukuran $22 \mathrm{~m}^{2}$ dan tipe $1 \mathrm{BR}$ dengan ukuran 28-34 $\mathrm{m}^{2}$. Fasilitas-fasilitas yang tersedia di Sentraland Bekasi diantaranya kolam renang, area taman bermain anak, jogging track, dan food court.

Mayoritas tipe unit di Sentraland adalah tipe studio. Hal ini menggambarkan rusunami ini diperuntukan untuk masyarakat yang masih sendiri ataupun keluarga muda. Tahap penjualan di Sentraland dibagi menjadi beberapa tahap, yaitu:

- Tahap pertama: tahap penjualan subsidi yang ditujukan untuk kelompok MBR. Kuota yang disediakan adalah $\pm 20 \%$ dari total unit di Sentraland Bekasi atau \pm 183 unit. Harga jual pada tahap pertama adalah $\mathrm{Rp} 8,4 \mathrm{juta} / \mathrm{m}^{2}$ atau $\pm \mathrm{Rp} 180 \mathrm{juta} / \mathrm{unit}$.

- Tahap kedua dan tahap selanjutnya: Sentraland dijual secara komersial dan tidak menyediakan fasilitas subsidi lagi. Pada tahap 2, unit di Sentraland dijual dengan harga Rp $10,6 \mathrm{juta} / \mathrm{m}^{2}$ atau $\pm \mathrm{Rp} 230$ juta/unit, sedangkan pada tahap ketiga dijual dengan harga $\mathrm{Rp}$ $11,6 \mathrm{juta} / \mathrm{m}^{2}$ atau $\pm \mathrm{Rp} 250 \mathrm{juta} / \mathrm{m}^{2}$.

\section{Analisa Lokasi Sentraland Bekasi}

Sentraland Bekasi berada dalam kawasan perumahan Pesona Metropolitan Bekasi. Kawasan perumahan ini berada di Jl. Raya Siliwangi yang merupakan jalan arteri primer. Kondisi jalan di depan kawasan Pesona Metropolitan Bekasi terbilang cukup ramai. Hal ini menggambarkan bahwa kawasan ini sedang berkembang.

Berdasarkan hasil pengamatan, Sentraland Bekasi diapit oleh 2 jalan tol. Pertama adalah jalan tol Jakarta - Cikampek yang berjarak $\pm 6 \mathrm{~km}$ dari Sentraland Bekasi dan dapat dicapai dalam waktu tempuh \pm 14 menit dengan kendaraan pribadi dan gerbang tol terdekat adalah gerbang tol Bekasi Barat 1. Kedua adalah jalan tol Lingkar Luar Timur yang berjarak $\pm 5 \mathrm{~km}$ dari Sentraland Bekasi dan dapat dicapai dalam waktu tempuh \pm 11 menit dengan kendaraan pribadi dan gerbang tol terdekat adalah gerbang tol Jatiasih.

Transportasi umum yang melewati depan kawasan perumahan Pesona Metropolitan Bekasi adalah angkutan kota seperti mikrolet K11 (Terminal Bekasi-Bantargebang), dan tidak ada angkutan yang masuk ke dalam kawasan perumahan Pesona Metropolitan Bekasi. Jarak dari pintu gerbang menuju Sentraland Bekasi berjarak \pm 87 meter. Stasiun terdekat dari Sentraland Bekasi adalah stasiun Bekasi yang berjarak $\pm 8 \mathrm{~km}$ dan dapat ditempuh dalam waktu \pm 21 menit dengan kendaraan. Dari hasil pengamatan di atas, aksesibilitas menuju dan dari Sentraland Bekasi tidak cukup mudah dicapai dengan transportasi umum. Transportasi umum yang dimiliki tidak bervariatif.

Dari hasil data di atas, aksesibilitas yang dimiliki Sentraland Bekasi cukup mudah dicapai baik dengan kendaraan pribadi namun sulit dicapai dengan transportasi umum. Dalam penelitian ini, faktor kemudahan aksesibilitas menjadi salah satu faktor yang diuji apakah kemudahan aksesibilitas mendorong penyerapan pasar di Sentraland Bekasi.

Berdasarkan hasil pemetaan, pusat-pusat kegiatan yang mendominasi di sekitar Sentraland Bekasi adalah kegiatan industi/pergudangan, kesehatan, dan pendidikan. Sedangkan mayoritas 
pusat kegiatan komersial berada di pusat kota Bekasi yang berjarak $\pm 7 \mathrm{~km}$ dari Sentraland Bekasi dan dapat ditempuh dalam waktu \pm 27 menit dengan kendaraan. Dari hasil pengamatan di atas, lokasi Sentraland Bekasi cukup jauh dari pusat kota Bekasi. Namun dalam konsep pengembangan Sentraland Bekasi, Sentraland menyediakan fasilitas pusat perbelanjaan di bawah hunian yang memberikan added value untuk Sentraland Bekasi. Sehingga walaupun Sentraland Bekasi jauh dari pusat kota, Sentraland Bekasi tetap memberikan kemudahan pada penghuninya layaknya tinggal dekat dengan pusat kota dengan kelengkapan fasilitas seperti di pusat kota.

\section{Tren Penjualan Sentraland Bekasi}

Sentraland telah melakukan penjualan sejak September 2016. Penjualan tahap pertama ditujukan untuk kelompok MBR dengan fasilitas subsidi yaitu KPR FLPP. Kuota yang disediakan pada tahap pertama \pm 184 unit atau 20\% dari total unit keseluruhan di Sentraland Bekasi.

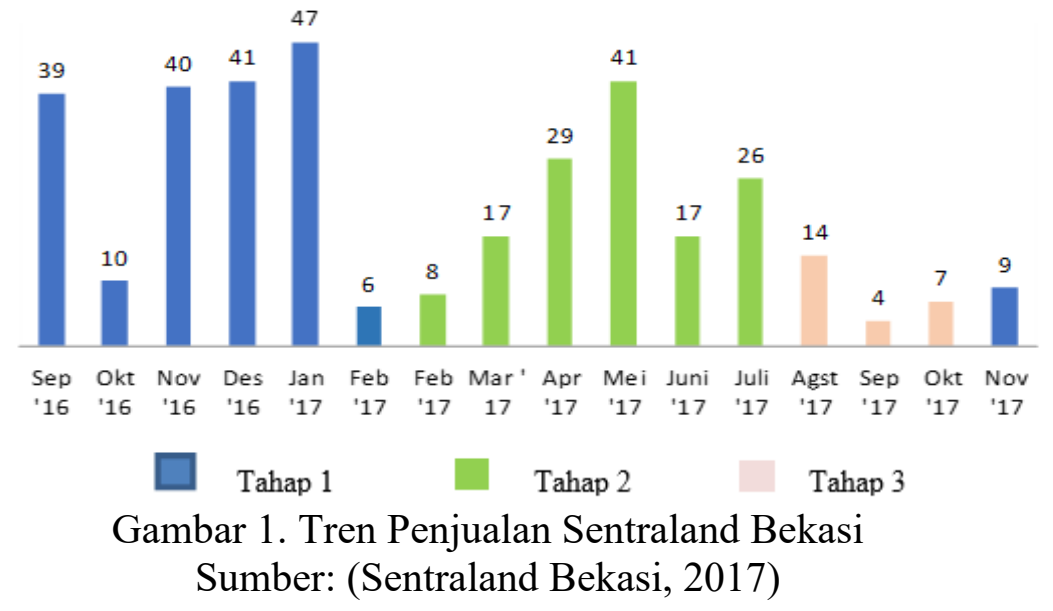

Diagram di atas menjelaskan bahwa pada tahap penjualan rusunami dengan subsidi terserap baik dalam waktu \pm 5 bulan penjualan. Pada tahap pertama, kuota unit bersubsidi terjual habis yaitu sebanyak 183 unit. Namun terjadi penurunan pada tahap berikutnya yang sudah dijual secara komersial dengan harga di atas $\mathrm{Rp} 10 \mathrm{juta} / \mathrm{m}^{2}$ atau di atas $\mathrm{Rp} 250 \mathrm{juta} / \mathrm{unit}$. Hal ini menggambarkan bahwa adanya ketidakmampuan atau kurang berminat pada Rusunami yang dijual dengan harga tersebut. Salah satu penyebabnya adalah preferensi masyarakat yang lebih memilih rumah tapak dan masih adanya rumah tapak di sekitar Sentraland yang dijual dengan harga yang lebih murah dibandingkan dengan harga jual Sentraland Bekasi yaitu \pm Rp $150-200$ juta/rumah.

\section{Profil Responden Pembeli Unit Rusunami di Sentraland Bekasi}

Mayoritas pembeli unit di Sentraland Bekasi adalah kelompok millenials yang belum berkeluarga dan masih tinggal dengan orangtua. Dari hasil ini diindikasikan adanya salah sasaran kepemilikan Rusunami bersubsidi. Hasil temuan ini diperkuat dengan hasil wawancara dengan Ibu Maya selaku manajer marketing Sentraland Bekasi, tidak sepenuhnya adalah keinginan kelompok millenials untuk membeli unit di Sentraland. Adanya indikasi orangtua mereka yang membeli unit di Sentraland namun hak miliknya atas nama anaknya. Kelompok MBR yang dimaksud Pemerintah tidak spesifik menunjuk kepada seseorang yang benar - benar membutuhkan hunian. Sehingga beberapa masyarakat kelas menengah ke atas memanfaatkan nama anaknya yang masuk dalam kriteria MBR versi Pemerintah.

Mayoritas jenis pekerjaan pembeli unit di Sentraland Bekasi adalah karyawan swasta dan PNS. Di samping itu, terdapat sekitar $12 \%$ pembeli bekerja sebagai buruh, $6 \%$ bekerja sebagai 
wiraswasta, dan sisanya bekerja sebagai di sektor lainnya. Temuan yang menarik adalah terdapat $2 \%$ responden berprofesi sebagai mahasiswa. Temuan ini semakin menguatkan bahwa terdapat beberapa kalangan menengah atau yang sudah memiliki hunian menggunakan nama anaknya agar bisa mendapatkan unit rusunami dengan harga murah dan mendapatkan fasilitas KPRFLPP.

Mayoritas responden (45\%) bekerja di Jakarta. Sedangkan 37\% responden bekerja di sekitar Bekasi dan 18\% responden bekerja di Narogong yang lokasinya sangat dekat dengan Sentraland Bekasi. Jika dibandingkan dengan harga hunian di Jakarta, harga hunian di Bekasi lebih murah dan masih tersedia banyak. Jarak antara Sentraland Bekasi dengan Jakarta Pusat (pusat ekonomi) adalah $\pm 28 \mathrm{~km}$ dan dapat ditempuh dalam waktu \pm 40 menit dengan kendaraan pribadi. Walaupun demikian pembeli rela membeli hunian di Sentraland Bekasi yang jauh dari Jakarta dengan harga murah. Temuan ini sesuai dengan teori Trade Off yaitu seseorang rela membayar lebih untuk perjalanan ke tempat kerja asalkan mendapatkan hunian dengan harga rumah.

\section{Faktor-faktor yang Mempengaruhi Keputusan Membeli Rusunami di Sentraland Bekasi}

Faktor-faktor yang dianggap mempengaruhi keputusan seseorang membeli hunian adalah harga yang terjangkau, aksesibilitas yang mudah, kedekatan dengan lokasi tempat kerja, fasilitas yang disediakan, kedekatan dengan pusat kota, dan kredibilitas developer yang terpercaya (Dasso \& Shiling, 1995). Faktor-faktor inilah yang akan menjadi alat ukur keputusan membeli di Sentraland Bekasi.

Tabel 2. Faktor-faktor yang Mempengaruhi Keputusan Membeli Rusunami di Sentraland Bekasi

\begin{tabular}{lcccc}
\hline \multicolumn{1}{c}{ Faktor } & $\boldsymbol{\mu}$ & $\mathbf{p}$-value & Kesimpulan & Tingkat Pengaruh \\
\hline Harga yang terjangkau & 4.30 & $0.00<0.05$ & Reject $H_{0}$ & Berpengaruh \\
\hline Aksesibilitas yang mudah & 2.90 & $0.29>0.05$ & Don't Reject $H_{0}$ & Tidak Berpengaruh \\
\hline $\begin{array}{l}\text { Kedekatan dengan lokasi } \\
\text { tempat kerja }\end{array}$ & 3.07 & $0.52>0.05$ & Don't Reject $H_{0}$ & Tidak Berpengaruh \\
\hline Fasilitas yang disediakan & 3.75 & $0.00<0.05$ & Reject $H_{0}$ & Berpengaruh \\
\hline Kedekatan dengan pusat kota & 2.56 & $0.00<0.05$ & Reject $H_{0}$ & Berpengaruh \\
\hline $\begin{array}{l}\text { Kredibilitas developer yang } \\
\text { terpercaya }\end{array}$ & 3.82 & $0.00<0.05$ & Reject $H_{0}$ & Berpengaruh \\
\hline
\end{tabular}

Tabel di atas menggambarkan faktor harga yang terjangkau adalah faktor yang sangat kuat mempengaruhi keputusan MBR membeli rusunami di Sentraland Bekasi. Selain faktor harga yang terjangkau, faktor fasilitas yang disediakan di Sentraland Bekasi seperti mall dan kredibilitas Perumnas sebagai developer Sentraland Bekasi merupakan faktor yang cukup kuat mempengaruhi MBR membeli rusunami di Sentraland Bekasi. Sedangkan faktor kedekatan dengan berpengaruh sangat lemah terhadap keputusan MBR membeli rusunami di Sentraland Bekasi. Faktor yang tidak berpengaruh terhadap keputusan MBR membeli rusunami di Sentraland Bekasi adalah faktor aksesibilitas dan kedekatan dengan tempat kerja.

Tabel 3. Peringkat yang Mempengaruhi Konsumen Membeli Rusunami di Sentraland Bekasi

\begin{tabular}{clcc}
\hline No & \multicolumn{1}{c}{ Faktor } & Rata-rata & Rank \\
\hline 1 & Harga jual yang terjangkau & 4.30 & 1 \\
\hline 2 & Kredibilitas developer yang terpercaya & 3.82 & 2 \\
\hline 3 & Fasilitas yang disediakan & 3.75 & 3 \\
\hline 4 & Kedekatan dengan pusat kota & 2.56 & 4 \\
\hline
\end{tabular}


Dari hasil analisis di atas, faktor harga jual yang terjangkau menjadi faktor yang paling berpengaruh terhadap keputusan konsumen membeli di Sentraland Bekasi. Harga jual per unit di Sentraland Bekasi tahap 1 masih terbilang cukup terjangkau untuk konsumen yaitu di bawah Rp 200 juta/unit. Harga jual tersebut masih sesuai dengan peraturan Kementerian no. 269/PMK.010/2015 yaitu di bawah Rp 250 juta/unit sehingga konsumen Sentraland bias mendapatkan bantuan subsidi berupa bebas PPn dan mendapatkan fasilitas KPR-FLPP. Akibat harga tersebut dan fasilitas cara pembayaran dengan KPR-FLPP, Sentraland Bekasi sangat diminati dari kelompok MBR hingga kalangan menengah ke atas.

Namun saat tahap 2 dan selanjutnya, penjualan di Sentraland Bekasi mengalami penurunan. Salah satu penyebabnya adalah harga jualnya yang meningkat yaitu di atas Rp 200 juta/unit dan sudah tidak disubsidi lagi. Dengan harga di atas Rp 200 juta/unit, Sentraland Bekasi menjadi tidak diminati lagi seperti pada tahap 1.

Selain itu, faktor kedua yang berpengaruh terhadap keputusan membeli di Sentraland Bekasi adalah kredibilitas Perumnas sebagai developer Sentraland Bekasi. Sebagian besar responden merasa aman mengivestasikan uangnya di Sentraland Bekasi saat mengetahui Perumnas adalah developernya.

Faktor ketiga yang juga mempengaruhi konsumen membeli di Sentraland Bekasi adalah terintegrasinya Sentraland Bekasi dengan mall. Menurut hasil wawancara dengan Ibu Maya, manager marketing Sentraland Bekasi, konsumen tidak bersedia jika mall tersebut dihilangkan. Hasil ini sejalan dengan hasil penelitian, bahwa faktor fasilitas yang disediakan menjadi salah satu faktor yang mempengaruhi konsumen membeli unit di Sentraland Bekasi.

\section{Gambaran Umum Teras Alun Alun, Vida Bekasi}

Kawasan Vida Bekasi berada di jalan Raya Siliwangi, Kelurahan Bojong Rawalambu, Kecamatan Rawalumbu. Vida Bekasi dikembangkan oleh Gunas Land di atas lahan seluas 130 Ha yang terdiri dari perumahan landed dan perumahan vertikal yaitu Teras Alun Alun. Kawasan Vida Bekasi memiliki 2 distrik, yaitu Bumipala (semula Grand Bekasi) dan Bumiwidari (kawasan Vida Bekasi). Bumipala adalah kawasan pertama yang dikembangkan oleh Vida Bekasi dan letaknya cukup jauh dari jalan Raya Siliwangi yaitu berjarak $\pm 5,1 \mathrm{~km}$. Sedangkan Bumiwidari adalah kawasan kedua yang dikembangkan dan letaknya adalah yang paling depan dan dekat dengan jalan Raya Siliwangi. Lokasi Teras Alun Alun (rusunami di Vida Bekasi) berada di kawasan pengembangan Bumipala.

Teras Alun Alun dibangun 5 lantai di atas lahan seluas $4.700 \mathrm{~m}^{2}$. Lantai dasar digunakan untuk fasilitas komersial, dan lantai 2-5 digunakan sebagai hunian. Teras Alun Alun hanya memiliki 1 tipe unit yang ditawarkan yaitu tipe 2BR ( 2 bedroom) dengan luas $28-40 \mathrm{~m}^{2}$. Masing-masing lantai untuk hunian terdapat 49 unit.

Fasilitas-fasilitas yang dimiliki Teras Alun Alun diantaranya children playground, daycare, communal space, komersial dan klinik. Selain itu Teras Alun Alun memiliki fasilitas yang tergabung dengan kawasan Vida Bekasi seperti arena Sportclub, pasar Anyar, tempat ibadah dan sekolah (Bina Nusantara).

\section{Analisa Lokasi Teras Alun Alun, Vida Bekasi}


Teras Alun Alun berada di dalam kawasan Vida Bekasi. Kawasan ini diapit oleh 2 jalan yaitu jalan Raya Siliwangi dan Jalan Raya Bantargebang Setu. Jarak Teras Alun Alun ke jalan Raya Siliwangi berjarak $\pm 5,1 \mathrm{~km}$, sedangkan jarak Teras Alun Alun ke jalan Raya Bantargebang Setu berjarak \pm 900 meter. Lokasi Teras Alun Alun tidak sebaik dengan lokasi Sentraland Bekasi karena cukup jauh dari jalan Arteri primer yaitu jalan Raya Siliwangi.

Berdasarkan hasil pengamatan, Vida Bekasi diapit oleh 2 jalan tol. Pertama adalah jalan tol Jakarta - Cikampek yang berjarak $\pm 6 \mathrm{~km}$ dari Vida Bekasi dan dapat dicapai dalam waktu tempuh \pm 14 menit dengan kendaraan pribadi dan gerbang tol terdekat adalah gerbang tol Bekasi Barat 1. Kedua adalah jalan tol Lingkar Luar Timur yang berjarak $\pm 5 \mathrm{~km}$ dari Vida Bekasi dan dapat dicapai dalam waktu tempuh \pm 11 menit dengan kendaraan pribadi dan gerbang tol terdekat adalah gerbang tol Jatiasih.

Transportasi umum yang melewati Vida Bekasi adalah angkutan kota seperti mikrolet K11 (Terminal Bekasi-Bantargebang). Angkutan ini melintas di Jalan Raya Siliwangi, sehingga cukup jauh diakses dari Teras Alun Alun yang berjarak $\pm 5,1 \mathrm{~km}$. Stasiun terdekat dari Sentraland dan Vida Bekasi adalah stasiun Bekasi yang berjarak $\pm 8 \mathrm{~km}$ dan dapat ditempuh dalam waktu \pm 21 menit dengan kendaraan. Ketersediaan transportasi umum di sekitar Teras Alun Alun cukup jauh dan sulit dicapai. Sehingga dapat disimpulkan aksesibilitas dari dan ke Teras Alun Alun tidak begitu baik dengan transportasi umum.

Dari hasil data di atas, aksesibilitas yang dimiliki Vida Bekasi cukup mudah dicapai baik dengan kendaraan pribadi namun pencapaian dengan transportasi umum tidak mudah. Dalam penelitian ini, faktor kemudahan aksesibilitas menjadi salah satu faktor yang diuji apakah kemudahan aksesibilitas mendorong penyerapan pasar di Vida Bekasi.

Pusat-pusat kegiatan yang mendominasi di sekitar Vida Bekasi adalah kegiatan industi/pergudangan, kesehatan, dan pendidikan. Sedangkan mayoritas pusat kegiatan komersial berada di pusat kota Bekasi. Selain itu dalam konsep pengembangan, kawasan Vida Bekasi akan dilengkapi dengan fasilitas komersial seperti Pasar Anyar dan ruko - ruko serta fasilitas pendidikan seperti Bina Nusantara yang memberikan added value pada kawasan ini.

Secara lokasi, jarak Vida Bekasi ke pusat kota Bekasi lebih jauh dibandingkan dengan Sentraland Bekasi. Jarak Vida Bekasi ke pusat kota Bekasi adalah $\pm 10,6 \mathrm{~km}$ dan dapat ditempuh dalam waktu \pm 34 menit dengan kendaraan.

\section{Tren Penjualan Teras Alun Alun, Vida Bekasi}

Berbeda dengan Sentraland, 100\% unit di Vida Bekasi ditujukan untuk kelompok MBR (Masyarakat Berpenghasilan Rendah). Jumlah unit yang tersedia adalah 164 unit dan dijual dengan harga $\mathrm{Rp} 8,4 \mathrm{juta} / \mathrm{m}^{2}$. Walaupun harga satuan unit sudah mengikuti peraturan Pemerintah, harga jual per unit yang ditawarkan Vida Bekasi cukup tinggi yaitu di atas Rp 300 juta/unit. Harga ini sudah tidak bebas PPn karena berada di atas harga Rp 250 juta/unit.

Penyebab harga jual unit Teras Alun Alun menjadi mahal walaupun sudah mengikuti peraturan Pemerintah adalah luas unitnya yang terlalu besar. Luas unit yang ditawarkan Teras Alun Alun melebihi luas unit rusunami subsidi yaitu $21-36 \mathrm{~m}^{2}$. 


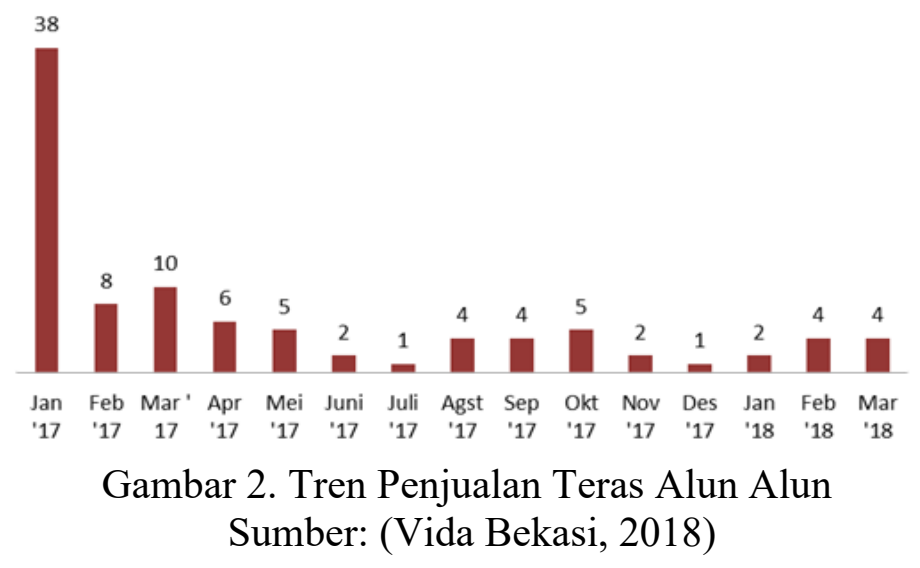

Jika dibandingkan dengan Sentraland Bekasi, hasil penjualan di Vida Bekasi tidak terserap dengan baik. Total unit terjual hingga bulan Maret 2018 adalah 96 unit. Selain itu menurut wawancara dengan Bapak Michael selaku marketing Vida Bekasi, mayoritas pembeli Teras Alun Alun berasal dari kelas menengah ke atas dan merupakan investor. Bahkan ada investor yang membeli beberapa unit di Teras Alun Alun yang kemudian akan disewakan kembali kepada orang lain. Dari hasil wawancara tersebut menjelaskan target Teras Alun Alun menjadi salah sasaran atau tidak sesuai dengan sasaran dalam peraturan Pemerintah.

\section{Profil Responden Lost Customer Teras Alun Alun, Vida Bekasi}

Mayoritas responden (62\%) berasal dari kelompok gen-x yaitu berusia 36-50 tahun, , 24\% dari kelompok millenials yang berusia 21-35 tahun, , dan sisanya dari kelompok baby boomers yang berusia di atas 50 tahun.

Mayoritas responden lost customer Teras Alun Alun tinggal di hunian dengan status sewa/kontrak. Kelompok terbesar berasal dari kelompok gen- $x$ yang tinggal di hunian sewa/kontrak. Walaupun demikian, terdapat $17 \%$ responden telah memiliki hunian sendiri. Kelompok inilah yang seharusnya tidak dapat membeli rusunami dengan harga subsidi/rusunami untuk kelompok MBR.

Mayoritas responden memiliki penghasilan di bawah Rp 7 juta, yaitu 42\% responden memiliki penghasilan Rp 3-5 juta, dan 35\% responden memiliki penghasilan Rp 5-7 juta. Hal ini sesuai dengan target peraturan Menteri Keuangan no. 269/PMK.010/2015 yaitu mereka yang memiliki penghasilan di bawah Rp 7 juta/ keluarga.

\section{Faktor-Faktor yang Mempengaruhi Keputusan Lost Customer Tidak Membeli Rusunami di Teras Alun Alun, Vida Bekasi}

Faktor - faktor yang mempengaruhi keputusan lost customer tidak mau membeli di Teras Alun Alun, Vida Bekasi didapat dari hasil kuesioner. Variabel pada kuesioner mengacu pada teori faktor-faktor yang mempengaruhi keputusan membeli yang sudah dikemukakan dalam Bab 2 . Kategori jawaban dalam kuesioner dibuat dalam range 1 - 5 (kurang setuju - sangat setuju), dan responden mengisi masing - masing jawaban sesuai dengan preferensi masing - masing. Dari kuesioner ini akan ditemukan mengapa Teras Alun Alun, Vida Bekasi kurang diminati khususnya oleh kelompok MBR.

Tabel 4. Faktor-faktor yang Mempengaruhi Keputusan Lost Customer Tidak Membeli Rusunami di Teras Alun Alun, Vida Bekasi 


\begin{tabular}{lcccc}
\hline \multicolumn{1}{c}{ Faktor } & $\boldsymbol{\mu}$ & p-value & Kesimpulan & Tingkat Pengaruh \\
\hline Harga yang mahal & 4.10 & $0.00<0.05$ & Reject $H_{0}$ & Berpengaruh \\
\hline Aksesibilitas yang kurang mudah & 3.98 & $0.00<0.05$ & Reject $H_{0}$ & Berpengaruh \\
\hline Fasilitas yang kurang lengkap & 3.06 & $0.48>0.05$ & Don't Reject $H_{0}$ & Tidak berpengaruh \\
\hline $\begin{array}{l}\text { Jauh dari pusat kota } \\
\text { Kredibilitas developer yang }\end{array}$ & 3.42 & $0.00<0.05$ & Reject $H_{0}$ & Berpengaruh \\
kurang terpercaya & 2.41 & $0.00<0.05$ & Reject $H_{0}$ & Berpengaruh \\
\hline $\begin{array}{l}\text { Preferensi rumah tapak } \\
\text { nat }\end{array}$ & 4.23 & $0.00<0.05$ & Reject $H_{0}$ & Berpengaruh \\
\hline
\end{tabular}

Hasil di atas menunjukan hasil rata-rata dari pendapat responden lost customer. Faktor adanya pilihan rumah tapak di sekitar Teras Alun Alun dengan harga yang lebih murah dan faktor harga jual yang mahal menjadi faktor yang berpengaruh sangat kuat terhadap keputusan lost customer tidak membeli di Teras Alun Alun. Selain itu, faktor aksesibilitas yang kurang mudah dan faktor lokasi Teras Alun Alun yang cukup jauh dari pusat kota Bekasi berpengaruh cukup kuat terhadap keputusan lost customer tidak membeli rusunami di Teras Alun Alun. Sedangkan kredibilitas Gunasland sebagai developer Teras Alun Alun berpengaruh lemah terhadap keputusan lost customer tidak membeli rusunami di Teras Alun Alun. Faktor kelengkapan fasilitas yang disediakan di Teras Alun Alun tidak berpengaruh terhadap keputusan lost customer tidak membeli di Teras Alun Alun.

Tabel 5. Peringkat Faktor-faktor yang Mempengaruhi Keputusan Lost Customer Tidak Membeli Rusunami di Teras Alun Alun, Vida Bekasi

\begin{tabular}{clcc}
\hline No & \multicolumn{1}{c}{ Faktor } & Rata-rata & Rank \\
\hline 1 & Preferensi rumah tapak & 4.23 & 1 \\
\hline 2 & Harga jual yang mahal & 4.10 & 2 \\
\hline 3 & Aksesibilitas yang kurang mudah & 3.98 & 3 \\
\hline 4 & Jauh dari pusat kota & 3.42 & 4 \\
\hline 5 & Kredibilitas developer yang kurang terpercaya & 2.41 & 5 \\
\hline
\end{tabular}

Dari hasil analisis di atas, faktor harga jual dan pesaing rumah tapak menjadi faktor yang sangat berpengaruh terhadap keputusan lost customer tidak membeli unit di Teras Alun Alun, Vida Bekasi.

Jika dibandingkan dengan Sentraland Bekasi, harga jual $/ \mathrm{m}^{2}$ Teras Alun Alun, Vida Bekasi sama dan sudah sesuai dengan peraturan Pemerintah yaitu $\mathrm{Rp} 8.400 .000,00$. Namun harga jual per unit Teras Alun Alun lebih mahal dibandingkan Sentraland Bekasi. Jika harga per unit Sentraland Bekasi bekisar Rp 184 - 300 juta, sedangkan harga per unit Teras Alun Alun mulai dari Rp 300 juta. Salah satu penyebabnya adalah luas unit yang ditawarkan Teras Alun Alun terlalu besar yaitu di atas $36 \mathrm{~m}^{2}$, sehingga harga jual per unitnya menjadi lebih mahal.

Harga jual Teras Alun Alun berada di atas Rp 250 juta/unit yang artinya harga jual ini tidak sesuai dengan peraturan yang mengatur syarat KPR FLPP (Peraturan Menteri Keuangan no. 269/PMK.010/2015). Harga jual Teras Alun Alun tidak bebas PPn, dan tidak mendapatkan 
bantuan subsidi dari Pemerintah. Hal ini juga menjadi salah satu faktor yang mempengaruhi lost customer khususnya kelompok MBR tidak berminat membeli rusunami di Teras Alun Alun.

Salah satu solusi agar harga jual Rusunami di Teras Alun Alun diminati dan dapat dijangkau oleh kelompok MBR adalah dengan mengecilkan luasan unit yang ditawarkan. Teras Alun Alun perlu menyediakan pilihan unit dengan luas antara 21-36 $\mathrm{m}^{2}$, sehingga harga jual per unit di Teras Alun Alun maksimal Rp 250 juta/unit.

Selain harga jual, rumah tapak masih menjadi prioritas hunian utama bagi konsumen. Hal ini sejalan dengan data dari rumah.123 dan urbanindo (Sentraland Bekasi, 2017) yang menyatakan bahwa mayoritas masyarakat masih lebih memilih hunian tapak dibandingkan hunian vertikal.

Ditambah lagi daerah sekitar Teras Alun Alun, Vida Bekasi masih memiliki pilihan rumah tapak yang cukup banyak dengan harga yang lebih murah dibandingkan dengan harga jual unit di Teras Alun Alun, Vida Bekasi. Sehingga tidak mengherankan jika masyarakat lebih memilih hunian tapak dibandingkan rusunami jika mereka masih bias mendapatkan hunian tapak dengan harga yang lebih murah. Berikut adalah beberapa pesaing hunian tapak dalam radius $15 \mathrm{~km}$ dari Teras Alun Alun, Vida Bekasi.

Tabel 6. Pesaing Rumah Tapak Sekitar Teras Alun Alun, Vida Bekasi

\begin{tabular}{|c|c|c|c|c|c|}
\hline No & Nama Perumahan & Pengembang & Tipe & Harga jual & $\begin{array}{l}\text { Harga/ } \mathbf{m}^{2} \\
\text { bangunan }\end{array}$ \\
\hline 1 & Bekasi Timur Regency & $\begin{array}{l}\text { PT Cakrawala } \\
\text { Nusa Dimensi }\end{array}$ & $22 / 60$ & Rp 141.000.000 & Rp 6.409.000 \\
\hline 2 & Mahkota Cimuning & $\begin{array}{l}\text { PT Anugrah Duta } \\
\text { Mandiri }\end{array}$ & $\begin{array}{c}30 / 63 \\
36 / 73,5 \\
38 / 77 \\
52 / 105 \\
\end{array}$ & $\begin{array}{l}\text { Rp 148.900.000 } \\
\text { Rp 179.900.000 } \\
\operatorname{Rp} 192.900 .000 \\
\operatorname{Rp} 262.000 .000 \\
\end{array}$ & $\begin{array}{l}R p 4.963 .000 \\
R p 4.997 .222 \\
R p 5.076 .315 \\
R p 5.038 .461 \\
\end{array}$ \\
\hline 3 & Grand Tamansari Bekasi & $\begin{array}{l}\text { PT Cahaya Graha } \\
\text { Lestari }\end{array}$ & $22 / 60$ & Rp 133.500.000 & $\operatorname{Rp} 6.068 .181$ \\
\hline 4 & Cahaya Darrusalam & $\begin{array}{l}\text { PT Cahaya } \\
\text { Indorahmat } \\
\text { Pratamajaya }\end{array}$ & $22 / 60$ & Rp 126.000.000 & Rp 5.727.272 \\
\hline 5 & Cibarusah Indah & & $22 / 60$ & Rp 123.000.000 & Rp 5.590.909 \\
\hline 6 & Firdaus Residence & PT Wildan Lestari & $30 / 60$ & $\mathrm{Rp} 126.500 .000$ & $\mathrm{Rp} 4.216 .666$ \\
\hline 7 & Puri Harmoni & Vista Land & $26 / 60$ & Rp 141.000.000 & Rp 5.423.076 \\
\hline 8 & Bumi Sakinah 4 & $\begin{array}{l}\text { PT Buana Media } \\
\text { Nusantara }\end{array}$ & $36 / 60$ & Rp 190.000.000 & Rp 5.277.777 \\
\hline 9 & Green Sentosa Asri & $\begin{array}{l}\text { PT Sakura } \\
\text { Sejahtera }\end{array}$ & $32 / 60$ & Rp 135.000.000 & Rp 4.218.750 \\
\hline 10 & Griya Srimahi Indah & & $22 / 60$ & Rp 148.500.000 & $\mathrm{Rp} 6.750 .000$ \\
\hline 11 & Grand Vista Cikarang & SPS Group & $29 / 60$ & Rp 141.000.000 & $\mathrm{Rp} 4.862 .068$ \\
\hline 12 & Citra Swarna Residence & $\begin{array}{l}\text { Citra Swarna } \\
\text { Group }\end{array}$ & $27 / 60$ & Rp 145.500.000 & Rp 5.388.888 \\
\hline 13 & Cahaya Sampora Lima & & $29 / 60$ & Rp 148.000.000 & Rp 5.103.488 \\
\hline
\end{tabular}

Hasil di atas menunjukan masih adanya banyak pilihan hunian rumah tapak dengan harga yang lebih murah yaitu di bawah Rp 200 juta. Sehingga tidak mengherankan jika masyarakat akan lebih memilih hunian tapak dibandingkan rusunami. Hunian tapak dengan harga jual maksimal Rp 148,5 juta di wilayah Jabodetabek masih mendapatkan fasilitas KPR-FLPP dan bebas PPn. 
Beberapa pesaing hunian tapak masih menjual huniannya di bawah Rp 148,5 juta. Hal ini menjadi pesaing terberat bagi Teras Alun Alun.

\section{KESIMPULAN DAN SARAN}

Faktor harga jual rusunami yang terjangkau yaitu di bawah Rp 200 juta/unit menjadi faktor yang berpengaruh sangat kuat terhadap keputusan kelompok MBR membeli Rusunami di Sentraland Bekasi, sedangkan faktor yang berpengaruh sangat kuat terhadap keputusan lost Customer tidak membeli rusunami di Teras Alun Alun adalah adanya pilihan rumah tapak dalam radius $15 \mathrm{~km}$ dari Teras Alun Alun dengan harga jual yang lebih murah yaitu di bawah Rp 200 juta/unit dan harga jual di Teras Alun Alun yang mahal yaitu di atas Rp 300 juta/unit. Terdapat 1 kesamaan faktor pada kedua lokasi penelitian yaitu faktor harga yang sangat berpengaruh kuat terhadap keputusan membeli. Sehingga faktor yang perlu dipertimbangkan developer dalam mengembangkan rusunami adalah:

- Harga yang terjangkau yaitu maksimal Rp 250 juta/unit

- Pilihan hunian tapak semakin sedikit atau harga hunian tapak sudah mahal.

Untuk mencapai harga jual per unit yang dapat dijangkau oleh kelompok MBR dan bebas PPn adalah dengan menyesuaikan ukuran unit rusunaminya. Salah satu solusinya adalah Teras Alun Alun perlu menyediakan unit dengan ukuran 21-36 $\mathrm{m} 2$ dan harga jual maksimal Rp 250 juta/unit, agar dapat dijangkau dan diminati oleh kelompok MBR.

\section{REFERENSI}

Badan Pusat Statistik Kota Bekasi. (n.d.). Jumlah Penduduk dan Laju Pertumbuhan kota Bekasi. Retrieved Februari 27, 2017, from Badan Pusat Statistik Kota Bekasi: https://bekasikota.bps.go.id/statictable/2016/12/20/47/jumlah-penduduk-dan-lajupertumbuhan-penduduk-menurut-kecamatan-di-kota-bekasi-2010-2014-dan-2015-.html

Dasso, J., \& Shiling, J. D. (1995). Real Estate Twelfth Edition. Unitted States: Prentice Hall.

Dirgantara, P. (2016). Evaluasi Sasaran Pasar Rusunami Bersubsidi di Kota Jakarta (studi kasus: Rusunami Kalibata City. Jakarta: Magister Teknik Perencanaan Universitas Tarumanagara.

Dody. (2015). Daftar Rusunami Murah di Jakarta versi Kemenpupera. Retrieved 8 17, 2017, from Rumahku: http://www.rumahku.com/artikel/read/daftar-rusunami-murah-di-jakartaversi-kemenpupera-412063

Erawan, A. (2017). Vida Bekasi Rilis Apartemen Subsidi : Teras Alun Alun. Retrieved 2 25, 2018, from Rumah Hokie: http://www.rumahhokie.com/beritaproperti/vida-bekasi-rilisapartemen-subsidi-teras-alun-alun/

Jurnal Tata Kota Bekasi. (2014). Antisipasi Backlog Rumah di Bekasi. Jurnal Tata Kota Bekasi edisi 03, 38-43.

Mendrofa, A., Wibowo, H., Sofyan, I., Hendrawan, T., \& Witria, W. (2017). Faktor - Faktor yang Berpengaruh Dalam Keputusan Pembelian Rumah untuk Masyarakat Berpenghasilan Rendah. Universitas Prasetiya Mulya.

Mudzakir, I. (2016). Perumnas Bangun Sentraland Bekasi Rp 220 Miliar. Retrieved 2 25, 2018, from Berita Satu: http://id.beritasatu.com/home/perumnas-bangun-sentraland-bekasirp220-miliar/148606

Nohed, D. A. (2013). Market Demand Analysis of Affordable Housing in Kuching and Samarahan Divisions. Universiti Malaysia Sarawak. 
PUPR, D. J. (2016). MAISONA (Media Informasi \& Komunikasi Penyediaan Perumahan). Jakarta: Kementerian PUPR.

Sentraland Bekasi. (2017). Market Feasibility Study Sentraland Bekasi. Bekasi, Jawa Barat, Indonesia. 